\title{
Horizontes pós-coloniais da Pedagogia do Oprimido e suas contribuições para os estudos curriculares
}

\author{
José Gllauco Smith Avelino de Lima'(D) \\ Marta Maria Castanho Almeida Pernambuco"l \\ (in memoriam)
}

RESUMO

Este artigo analisa as afinidades entre o pensamento pedagógico de Paulo Freire e as teorias pós-coloniais. Parte do entendimento de que a proposta problematizadora de educação paulofreireana questiona e traz a possibilidade da desconstrução das várias formas contemporâneas da colonialidade produzidas por meio de ações educacionais que reforçam condições de opressão que cerceiam a realização da dignidade humana. Quanto ao trato metodológico, prioriza a análise bibliográfica, dialogando com autores como Paulo Freire e alguns de seus intérpretes e com autores considerados pós-colonialistas. Como considerações, destaca que as afinidades entre o ideário pedagógico de Paulo Freire e as teorias pós-coloniais corroboram uma narrativa educacional como projeto político e pós-colonialista capaz de recuperar histórias locais e suas contradições como produtoras de um conhecimento insubmisso às plurais formas de opressão e subalternidade que inviabilizam a vida digna e a humanização das pessoas.

\section{PALAVRAS-CHAVE}

educação; Paulo Freire; teorias pós-coloniais.

Instituto Federal de Educação, Ciência e Tecnologia do Rio Grande do Norte, São Paulo do Potengi, RN, Brasil.

"Universidade Federal do Rio Grande do Norte, Natal, RN, Brasil. 


\title{
POST-COLONIAL HORIZONS OF THE PEDAGOGY OF THE OPRESSED AND ITS CONTRIBUTIONS TO CURRICULAR STUDIES
}

\begin{abstract}
This article analyzes the affinities between the pedagogical thought of Paulo Freire and the postcolonial theories. It is based on the understanding that his problematizing proposal questions and brings the possibility of deconstructing various contemporary forms of coloniality produced through educational actions that reinforce conditions of oppression that hinder the achievement of human dignity. As for the methodological treatment, this work prioritizes the bibliographic analysis, dialoguing with authors such as Paulo Freire and some of his interpreters, and with authors considered post-colonialists. As comments, it points out that the affinities between Paulo Freire's pedagogical ideology and postcolonial theories corroborate an educational narrative as a political and postcolonialist project capable of recovering local histories and their contradictions as producers of an knowledge unsubmissive to the many forms of oppression and subalternity that make the dignified life and people's humanization unfeasible.
\end{abstract}

\section{KEYWORDS}

education; Paulo Freire; postcolonial theories.

\section{HORIZONTES POST-COLONIALES DE \\ LA PEDAGOGÍA DEL OPRIMIDO Y SUS CONTRIBUCIONES PARA LOS ESTUDIOS CURRICULAR}

\section{RESUMEN}

Este artículo analiza las afinidades entre el pensamiento pedagógico de Paulo Freire y las teorías postcoloniales. Parte del entendimiento de que la propuesta problematizadora de educación paulofreireana cuestiona y trae la posibilidad de la deconstrucción de las diversas formas contemporáneas de la colonialidad producidas por medio de acciones educativas que refuerzan condiciones de opresión que cercenan la realización de la dignidad humana. En cuanto al trato metodológico, prioriza el análisis bibliográfico, dialogando con autores como Paulo Freire y algunos de sus intérpretes y con autores considerados post-colonialistas. Como consideraciones, destaca que las afinidades entre el ideario pedagógico de Paulo Freire y las teorías postcoloniales corroboran una narrativa educativa como proyecto político y post-colonialista capaz de recuperar historias locales y sus contradicciones como productoras de un conocimiento insumiso a las plurales formas de opresión y subalternidad que inviabilizan la vida digna y la humanización de las personas.

PALABRAS CLAVE

educación; Paulo Freire; teorías post-coloniales. 


\section{CONSIDERAÇÕES INICIAIS}

O artigo que ora se abre ao diálogo pretende evidenciar as afinidades pós-coloniais da pedagogia política de Paulo Freire, partindo do entendimento de que sua proposta crítico-problematizadora de educação, evidenciada em sua obra Pedagogia do Oprimido, oportuniza o questionamento e a possibilidade gradual de desconstrução das diversas manifestações contemporâneas da colonialidade ${ }^{1}$, produzidas e reproduzidas por meio de práticas socioeducacionais que ainda reforçam condições de opressão e de subalternidade que até hoje cerceiam a plena realização da dignidade humana.

Nessa perspectiva, o presente texto está situado no âmbito dos estudos pós-coloniais, referencial teórico e político que busca a problematização do mundo social contemporâneo a partir da discussão sobre a colonialidade e de seus efeitos nas diferentes esferas da atividade humana. Com base nisso, cabe acentuar que as pesquisas e as práticas fundamentadas nas teorias pós-colonialistas vêm cooperando para a elaboração de reflexões propulsoras de um debate crítico em torno dos problemas de um mundo formatado pelo colonialismo e pelo imperialismo nas mais diferentes instâncias da vida social (Quayson, 2000) e, dentre elas, o campo educacional formal e não formal em suas diferentes manifestações teóricas e práticas do plano curricular.

Mediatizados por esse pensamento, importante se faz assinalar que é no interior desse panorama que inserimos as discussões sobre a Pedagogia do Oprimido em suas afinidades com as reflexões pós-coloniais, tendo em vista que, consoante argumentamos, a teorização político-educacional nela desenvolvida pode contribuir para a problematização das relações neocoloniais que se desdobram na tessitura socioeducacional contemporânea, especialmente daquelas que se desenvolvem no espaço-tempo curricular da escola.

Diante disso, convém registrar que a discussão em tela está alocada nos marcos da pesquisa bibliográfica, por meio da qual estabelecemos interlocuções com intelectuais considerados pós-coloniais, a exemplo de Hugo Achugar, Gayatri Spivak, Vandana Shiva e Boaventura de Sousa Santos, para citar alguns. O diálogo com esses e outros pensadores possibilitou (re)afirmar a teoria e a prática político- pedagógicas de Paulo Freire como possibilidades concretas para o desdobramento de uma práxis socioeducacional pós-colonialista estreitamente vinculada à problematização em torno daquilo que foi ocultado e silenciado para oprimir, de modo a suscitar o questionamento e a desconstrução de práticas sociais e discursos legitimadores das inúmeras condições de opressão e subalternidade que continuam a

1 Utilizamos o termo colonialidade no sentido empregado por Aníbal Quijano (2010), expressando o argumento de que, como processo, a colonialidade se revela como extensão do poder colonial que continuou a existir mesmo após a independência política das antigas colônias. Trata-se de relações de exploração, de opressão e de subalternidade que se manifestam de formas variadas no contexto societário contemporâneo, criando, sustentando e reproduzindo novas relações de poder e de dominação tanto entre grupos e categorias sociais quanto entre Estados e Nações. 
usurpar a liberdade e a consciência dos sujeitos em relação a si mesmos e aos muitos mundos de vida que lhes são inerentes.

$\mathrm{O}$ artigo em realce está didaticamente organizado em três seções. A primeira delas aborda o campo de estudos curriculares a partir de uma vertente sociopolítica, enfatizando as constantes disputas axiológicas e epistemológicas entre grupos sociais sobre o que deve ser considerado como conhecimento legitimo para compor a estrutura curricular. A segunda traz a interpretação da Pedagogia do Oprimido como texto pós-colonial e suas contribuições para os estudos curriculares. A terceira e última seção sintetiza o nosso posicionamento quanto ao objeto deste trabalho: o de posicionar a leitura pós-colonial da Pedagogia do Oprimido como contribuição relevante para o desencadeamento de práticas curriculares problematizadoras dos matizes neocoloniais ainda circunscritos na atmosfera da escola contemporânea.

\section{SOBRE O CAMPO CURRICULAR}

Contemporaneamente, os estudos sobre o currículo escolar apresentam uma variedade significativa de perspectivas de análise, o que contribui para reconhecermos o caráter complexo e multirreferenciado das pesquisas curriculares. Falamos em campo curricular por compreendermos o currículo como um lugar de correlação de forças, no interior do qual se desencadeiam relações de poder que dão contorno a uma esfera socioeducacional em permanente disputa, seja do ponto de vista epistemológico, seja do mirante axiológico que o envolve em seus aspectos mais amplos.

Dizer que o currículo faz parte de um campo social em permanente disputa oportuniza entendê-lo como um espaço no qual diferentes agentes buscam produzir, reproduzir e legitimar determinadas concepções sobre o plano curricular. Em última instância, isso significa a tentativa da consolidação em torno de certas concepções de mundo com vistas à produção de consenso e hegemonia no âmbito das ideias pedagógicas e, por extensão, das práticas educacionais, já que o plano curricular opera como o núcleo e o espaço central mais estruturante da função da escola.

Sendo o currículo o espaço central mais estruturante da função da escola, as discussões sobre quais devem ser seus conteúdos são polissêmicas, gerando, nesses termos, permanentes embates em torno daquilo que se considera necessário conhecer em dado momento sócio-histórico. Em decorrência disso, o currículo passa a ser alvo de disputas das mais diversas, constituindo-se em um conflituoso microcosmo no interior do campo científico.

Bourdieu (1983, 2004,2005a, 2005b), ao refletir sobre os diferentes campos constitutivos do espaço social, observa que o campo científico - do qual o campo curricular é parte integrante - se expressa como um microcosmo da sociedade perpassado por relações de poder e dominação, no qual seus agentes se posicionam em função da quantidade de capital cultural acumulado e legitimado no interior do campo em que estão inseridos. Então, quanto maior for o quantum desse tipo de capital mobilizado por um grupo de agentes, mais elevada será a posição desses indivíduos na pirâmide social que estrutura o campo e, consequentemente, mais influente será o poder de classificação, hierarquização e legitimação sobre os bens 
produzidos no campo do qual fazem parte. Nas palavras de Nogueira e Nogueira (2009), campo é um conceito utilizado por Pierre Bourdieu para se referir

[...] a certos espaços de posições sociais nos quais determinado tipo de bem é produzido, consumido e classificado. [...]. No interior desses setores ou campos da realidade social, os indivíduos envolvidos passam, então, a lutar pelo controle da produção e, sobretudo, pelo direito de legitimamente classificarem e hierarquizarem os bens produzidos. (Nogueira e Nogueira, 2009. p. 31)

É no cerne dessa discussão, pois, que entendemos o conjunto dos debates que se desdobram sobre o que seja currículo, tendo em vista que seus significados emergem de uma arena conflituosa, instável e em constante desacordo, o que nos leva a considerar o currículo como prática social envolta por disputas que resvala para a construção de um conceito polissêmico e multirreferenciado, como pontuamos anteriormente.

Na mesma direção, Goodson (2012) acentua que o currículo é palco no qual contracenam-se tradição e ruptura, continuidades e descontinuidades, traduzindo-se em um espaço por meio do qual diferentes visões de mundo, de homem e de sociedade disputam hegemonia e incidem, diretamente, na elaboração de sentidos para palavras como educação, escola, conhecimento, currículo, ensino e aprendizagem, as quais, além de constituírem o vocabulário pedagógico de uma época determinada, condicionam a ação formativa escolar que, por sua vez, produz efeitos de poder sobre pessoas, construindo identidades e subjetividades sociais específicas.

Com essa reflexão, Goodson (2012) demonstra o currículo como arena de correlação de forças não apenas epistemológica, mas também sociopolítica, uma vez que se trata de

[...] um processo constituído de conflitos e lutas entre diferentes tradições e diferentes concepções sociais. [Um campo] no qual os diferentes grupos se digladiam para impor seus pontos de vista sobre qual é o conhecimento digno de ser transmitido às futuras gerações. (Goodson, 2012, p. 8-9)

Assim, é coerente considerar o campo do currículo como uma esfera do campo científico, cujos agentes, possuidores de certos níveis de capital cultural especialmente - buscam validar concepções sobre a teorização curricular, pondo em disputa, por assim dizer, quem tem a autoridade legítima para tornar hegemônicas determinadas interpretações sobre o que é currículo. Esse campo intelectual, conforme escrevem Lopes e Macedo (2005, p. 18), "[...] é um campo produtor de teorias sobre currículos, legitimadas como tais pelas lutas concorrenciais nesse mesmo campo".

Em decorrência dessas reflexões, e uma vez que estamos situados em um campo intelectual em constantes disputas éticas, políticas e epistemológicas no que concerne à definição do que seja currículo, consideramos pertinente evidenciar o fato de que adentrar no âmbito dos estudos curriculares significa posicionarmo-nos para além de uma acepção estritamente técnico-procedimental. Isso nos permite adotar um entendimento de currículo como texto sociocultural e político-epistêmico 
que compreende interesses e visões de mundo nem sempre consensuais, as quais moldam identidades individuais e coletivas, inscrevendo e afirmando determinados valores em estreita relação com as ideias dominantes presentes na dinâmica macrossocietária em que está inserido o sistema educacional em linhas gerais.

Corroboramos, desse modo, uma compreensão crítica da prática educativa, na qual o currículo

[...] não é um elemento inocente e neutro de transmissão desinteressada do conhecimento social. O currículo está implicado em relações de poder, o currículo transmite visões sociais particulares e interessadas, o currículo produz identidades individuais e sociais particulares. O currículo não é um elemento transcendente e atemporal - ele tem uma história, vinculada a formas específicas e contingentes de organização da sociedade e da educação. (Moreira e Silva, 2008, p. 7-8)

Nesse entendimento, o currículo constitui-se num artefato sociocultural construído por meio dos embates políticos desencadeados por grupos e categorias sociais na busca pela legitimidade científica de suas visões de mundo. Configura-se, assim, em um campo social hierarquizado, no qual seus agentes buscam obter consenso para a consolidação de uma dada hegemonia em torno do que é necessário conhecer, ou, de modo mais radical, um espaço no qual a pergunta crucial é: "tem mais valor o conhecimento de quem?" (Apple e Buras, 2008, p. 9).

A compreensão desse pertinente questionamento nos desloca para a análise das conexões entre educação e sociedade, posto que a correlação de forças existente na esfera curricular reflete a distribuição desigual dos poderes político, econômico e cultural no seio de dado arranjo societário, contribuindo, assim, para tornar assimétricos e hierarquizados os conhecimentos presentes na arena curricular legitimada. Com esse pensamento, o currículo transforma-se em espaço de tensão e conflito em meio a projetos socioeducacionais antagônicos, ou seja, revela o embate entre concepções reprodutivistas e emancipatórias, cada qual com suas visões de mundo, de homem, de sociedade e de educação que lhes são específicas.

Essas constantes crises entre projetos societários antagônicos, refletidas no interior do campo científico, contribuem para endossar as intensas disputas em torno daquilo que se considera conhecimento legitimo sobre alguma realidade específica, seja natural ou social. O espaço científico, e, neste, o campo curricular, também se mostra inscrito na dualidade conservação-mudança, por meio da qual aqueles agentes que já ocupam posições dominantes tenderão a adotar estratégias de conservação de sua localização na hierarquia do campo e, por extensão, da manutenção de sua autoridade no que se refere aos critérios de classificação dos bens materiais e simbólicos nele produzidos (no caso do campo científico, a autoridade legítima para afirmar o que vale como conhecimento). Esses agentes estarão inclinados, portanto, a reproduzir as estruturas internas que dão sustentabilidade ao microcosmo social em que se acham inseridos (Bourdieu, 1983).

Como expressão dessas tensões, o campo curricular apresenta tendências não apenas diferentes, mas também antagônicas no que respeita à interpretação sobre o 
que seja currículo. Em decorrência disso, a polifonia de vozes que ecoa nesse campo reverbera os múltiplos fundamentos éticos, políticos, econômicos e epistemológicos que podem vir, a depender da definição curricular adotada consciente ou inconscientemente, a alicerçar o fazer pedagógico e a orientar o arranjo das disciplinas com os conteúdos que lhes são inerentes, como também a maneira como se ensina e como se entende a construção da aprendizagem e do conhecimento.

Em face disso, e no que tangencia a discussão sobre os enfoques curriculares especificamente, diversos pesquisadores em história do currículo se empenharam em demonstrar e problematizar várias das tendências no âmbito das pesquisas em currículo, procurando explicitar características gerais, conceitos e definições por elas enfatizados e as possíveis implicações na prática formativa das escolas. Nesse movimento, e tendo em vista a diversidade de enfoques, tais autores também evidenciaram que não é plausível responder, em absoluto, ao que é currículo, haja vista que cada definição está vinculada a uma tendência teórica específica, explicitando, pois, sentidos e significados curriculares sempre parciais e localizados social e historicamente. Assim,

cada nova definição não é apenas uma nova forma de descrever o objeto currículo, mas parte de um argumento mais amplo no qual a definição se insere. A nova definição se posiciona, seja radicalmente contra, seja explicitando suas insuficiências, em relação às definições anteriores, mantendo-se ou não no mesmo horizonte teórico delas. (Lopes e Macedo, 2011, p. 20, grifos do original)

Em Documentos de Identidade: uma introdução às teorias do currículo, Tomaz Tadeu da Silva (2011) ressalta, a exemplo das autoras supracitadas, o fato de que não podemos dizer o que é currículo em sua essência. Para esse pesquisador, um discurso sobre o currículo, mesmo que centralize suas atenções em apenas descrevê-lo tal como realmente é, não faz outra atividade que não produzir uma noção particularizada sobre o que supostamente venha a ser o currículo. Nesse raciocínio, o próprio ato da descrição já é, em si, uma criação, o que nos conduz para a afirmação de que "[...] a teoria está envolvida num processo circular: ela descreve como uma descoberta algo que ela própria criou" (Silva, 2011, p. 12, grifo do original).

Em conformidade a esse pensamento, qualquer enfoque dado ao currículo sempre será passível de questionamentos, seja para refutá-lo, seja para ampliá-lo e ressignificá-lo a partir de inúmeras construções e desconstruções, continuidades e descontinuidades, permanências e rupturas, acirrando, por assim dizer, as disputas pela autoridade legítima em afirmar o que seja currículo no interior desse campo intelectual. Destarte, ao entendermos as teorizações curriculares como construtos linguísticos, como nos faz crer Silva (2011), concebemo-las como textos que produzem noções especializadas sobre currículo, e, por consequência, efeitos de verdade que se desdobram no planejamento e na prática curricular propriamente ditos.

Cabe esclarecer, consoante à argumentação anteriormente delineada, que este estudo está posicionado no interior do debate curricular pós-colonialista, que, segundo Silva (2011,p. 127), abraça uma concepção da prática educacional questionadora das "[...] relações de poder e [d] as formas de conhecimento que colocaram 
o sujeito imperial europeu na sua posição atual de privilégio [...]”. Nesse sentido, concentramo-nos na reflexão sobre como a Pedagogia do Oprimido, analisada à luz das teorias pós-colonialistas, pode contribuir para iniciar um projeto de educação endereçado à descolonização cognitiva e à descolonização do ser, perpetradas por práticas educacionais bancárias que, a despeito das transformações e metamorfoses curriculares contemporâneas, ainda são moldadas por resquícios epistemológicos coloniais que "[...] desumanizam o sujeito, transformando-o em coisa e alienando-o de sua cultura [e] de sua realidade" (Mota Neto, 2016, p. 174).

Em decorrência disso, corroboramos a pertinência da discussão sobre um currículo pós-colonial alicerçado na práxis político-pedagógica de Paulo Freire, ressaltando sua metodologia de construção de temas e contratemas geradores como pontes para um quefazer curricular alinhado à problematização da colonialidade por meio de sua concepção crítico-conscientizadora de educação.

\section{A PEDAGOGIA DO OPRIMIDO COMO TEXTO PÓS-COLONIAL: UMA PROPOSTA CURRICULAR FORJADA A PARTIR DAS ENUNCIAÇÕES DOS ESFARRAPADOS DO MUNDO}

Em interessante reflexão filosófica, Hannah Arendt (1987) assinalou que o ser humano, quando privado do espaço público, recolhe-se ao mundo do pensamento, lugar no qual sua liberdade não pode ser usurpada, a menos que lhe tirem a vida. Para a pensadora alemã, privar o ser humano de sua liberdade é pré-condição para colocá-lo em situação de escravização. Exemplos históricos dessa afirmativa não nos passam despercebidos, dentre estes, o de Paulo Freire, para quem o Golpe Civil-Militar, deflagrado no Brasil no ano de 1964, negou-lhe o espaço público brasileiro, impondo-lhe o exílio e impelindo-o ao recolhimento e ao espaço privado de seu pensamento. Dessa incursão subjetiva, e amparado nas experiências político-pedagógicas anteriores, nasceu a Pedagogia do Oprimido, livro de maior repercussão intelectual de toda a sua obra escrita (Lima, 2011).

Esse livro foi escrito nos fins da década de 1960, durante os anos iniciais do exílio de Paulo Freire no Chile. Sua primeira publicação ocorreu no ano de 1970, em língua inglesa, nos Estados Unidos, sendo, depois, traduzida para mais de trinta idiomas. Foi escrita em um contexto sócio-histórico e subjetivo de homens e mulheres na busca daquilo a que Paulo Freire denominou vocação ontológica do ser humano, a do ser mais. O espírito desse tempo foi expresso na luta pela independência dos povos africanos, os quais se rebelavam contra o domínio colonialista europeu (inglês, francês e português); no movimento de mulheres que lutavam por maior igualdade social perante os homens, redimensionando profundamente as relações de gênero; nos muitos movimentos antirracistas, libertários, antiditatoriais e anti-imperialistas espalhados pelo mundo, a exemplo do movimento de maio de 1968 na França (Streck, 2009).

Todos esses movimentos, e outros, como a Primavera de Praga; os intensos movimentos estudantis brasileiros contra o regime ditatorial; a luta por direitos civis e sociais no coração do império estadunidense, por exemplo, contestavam os status quo social em que se localizavam, questionando e denunciando as estruturas 
de opressão que impediam homens e mulheres de ser mais, no sentido paulofreireano desse termo. Ademais, não podemos esquecer que a Pedagogia do Oprimido reflete, também, as preocupações de Paulo Freire quanto aos contextos da América Latina, especialmente aos do Brasil e de sua Região Nordeste, todos eles marcados pela dominação imperial, pelas estruturas sociais produtoras de agudas desigualdades e pela expansão de regimes políticos ditatoriais implantados a partir de 1964.

Ao escrever a Pedagogia do Oprimido, Paulo Freire

[...] fez mais do que oferecer um livro perturbador a respeito da educação. Ele instigou os educadores e estudantes a que mudássemos a nós mesmos na história e a mudarmos o modo como ensinamos. Para muitos de nós, esse livro foi um guia e uma inspiração no combate ao autoritarismo da educação. Deu origem, também, a um movimento internacional de educadores que querem transformar as sociedades dentro das quais ensinam. (Shor, 1996. p. 566)

Desse modo, a Pedagogia do Oprimido promoveu uma inflexão nas teorias e nas práticas pedagógicas na segunda metade do século $\mathrm{XX}$ ao apresentar as bases antropológicas de uma educação insubmissa a quaisquer formas de dominação, de opressão e de subalternidade, oportunizando a reescrita de uma narrativa da educação como projeto político capaz de romper com as plurais formas de desumanização e com os diversos matizes da colonialidade, ampliando a discussão em torno de princípios e de práticas socioeducacionais que privilegiam a dignidade humana, a liberdade e a justiça social. Daí porque defendeu uma educação como prática da liberdade propulsora de uma consciência crítica capaz de promover a inserção, no centro do palco histórico, dos oprimidos, sujeitos invisibilizados e silenciados durante séculos de opressão colonial/imperial.

Nas palavras de Freire (2005), a pedagogia do oprimido é

[...] aquela que tem de ser forjada com ele e não para ele, enquanto homens ou povos, na luta incessante de recuperação de sua humanidade. Pedagogia que faça da opressão e de suas causas objeto de reflexão dos oprimidos, de que resultará o seu engajamento necessário na luta por sua libertação, em que esta pedagogia se fará e refará. (Freire, 2005, p. 34, grifos do original)

A partir dessas palavras, reconhecemos que a obra traz em seu âmago não somente a necessidade do protagonismo das classes dominadas no projeto de mudança social, mas, ao mesmo tempo, a noção do protagonismo cognitivo dos oprimidos no próprio curso de construção do conhecimento, ou seja, no processo de "[...] aprender a escrever a sua vida, como autor e como testemunha de sua história, isto é, biografar-se, existenciar-se, historicizar-se" (Fiori, 2005, p. 8). Afinal, como bem salientou Santos (2008), não há a possibilidade de uma justiça social global sem uma concomitante justiça cognitiva global.

No rastro desse raciocínio, a educação como prática da liberdade defendida por Paulo Freire em seu livro Pedagogia do Oprimido, assim como em seus trabalhos anteriores, significa pronunciar criticamente o mundo e modificá-lo por meio do 
engajamento ativo em face de problemáticas de ordem social, cultural, política, econômica e epistêmica, tendo em vista que, com a palavra, o ser humano se faz humano e, ao dizê-la, assume conscientemente sua condição de humanidade, desconstruindo situações de subalternidade, de invisibilidade e de silenciamento. Reside aqui, portanto, a razão pela qual a pedagogia do oprimido é também uma pedagogia do subalterno, pois permite aos oprimidos e subalternizados o direito à voz, à escuta e à visibilidade como elementos necessários à emancipação individual e coletiva.

Mota Neto (2016, p. 213) se mostra sensível a essa questão ao argumentar que o diálogo, em Paulo Freire, representa um momento crucial por meio do qual quem é impedido de falar possa falar; quem é impedido de ser escutado possa se fazer ouvir; e quem está em situações de invisibilidade possa ser visto. Na perspectiva desse autor, a pedagogia dialogal paulofreireana é uma das características mais potentes de uma educação decolonial ${ }^{2}$, pois "[...] possibilita que o outro negado desenvolva o seu direito de falar, se expressar, se posicionar, superando as barreiras do silêncio impostas pela modernidade/colonialidade".

Diante disso, cabe-nos indagar: como pode efetivar-se, em termos práticos, essa pedagogia do oprimido que também pode ser uma pedagogia do subalterno?

No desdobrar da teorização político-pedagógica desenvolvida por Paulo Freire na Pedagogia do Oprimido, particularmente no Capítulo III - A dialogicidade, essência da educação como prática da liberdade —, o educador pernambucano oportuniza a reflexão sobre a concretude de sua perspectiva curricular popular crítica, enfatizando o diagnóstico em torno da materialidade da realidade social em suas diferentes configurações como ponto de partida para a construção de um curriculo encarnado (Lima, 2014) nas negatividades da existência bumana (Gouvêa da Silva, 2004) como possibilidade para o questionamento e a superação das muitas situações existenciais de opressão e de subalternidade por meio da reorientação humanista dos conteúdos escolares.

Em outros termos, a busca pelos temas e contratemas geradores exige, necessariamente, o diálogo com a esfera do mundo vivido, no sentido da ação-reflexão- ação combinada à denúncia de práticas desumanizadoras que interditam o ser mais dos sujeitos e, ao mesmo tempo, conectada ao anúncio de novas ações condutoras para condições de humanização das pessoas e de seus universos de vida. Ou seja, a pesquisa sobre o universo temático, a tematização e a problematização, viabilizadas pelo diálogo com a realidade social concreta, são três operadores cognitivo-políticos que, inter-relacionados de modo interdisciplinar, podem acionar a passagem de uma pedagogia do oprimido/subalterno para uma pedagogia dos seres humanos em processo permanente de humanização e de libertação (Freire, 2005).

2 No âmbito dos estudos sobre colonialidade, alguns autores optam pelo termo decolonialidade, enquanto outros preferem o termo pós-colonialidade. Não adentraremos no mérito dessa discussão por entendermos que: (a) apesar das diferenças de natureza semântica e política, ambos os termos e as reflexões que deles decorrem trazem importantes contribuições para a problematização sobre o fenômeno da colonialidade contemporânea; e (b) configura um debate que foge ao objeto de análise deste artigo. 
A Pedagogia do Oprimido nos consente entender essas três etapas nos termos de uma construção curricular coletiva, cuja originalidade epistemológica está pautada na interdisciplinaridade, na dialogicidade, na politicidade e na ética da libertação, elementos estes capazes de movimentar e de concretizar ações curriculares críticas, tanto no plano do cognitivo quanto no plano do social em seus muitos matizes. Sobre isso, nos ensina Freire (2005):

Esta prática implica, por isto mesmo, que o acercamento às massas populares se faça, não para levar-lhes uma mensagem salvadora, em forma de conteúdo a ser depositado, mas, para, em diálogo com elas, conhecer, não só a objetividade em que estão, mas a consciência que tenham desta objetividade; os vários níveis de percepção de si mesmos e do mundo em que e com que estão. [...]. Nosso papel não é falar ao povo sobre a nossa visão de mundo, ou tentar impô-la a ele, mas dialogar com ele sobre a sua e a nossa. Temos de estar convencidos de que a sua visão do mundo, que se manifesta nas várias formas de sua ação, refletea sua situação no mundo, em que se constitui. A ação educativa e política não pode prescindir do conhecimento crítico dessa situação, sob pena de se fazer bancária ou de pregar no deserto. (Freire, 2005, p. 99-100, grifos do original)

Em sua efetividade prática, um currículo pós-colonial valoriza a voz e as percepções de mundo dos sujeitos como ponto de partida para o desenvolvimento das atividades curriculares. E, conforme podemos apreender das palavras de Paulo Freire acima registradas, fundamenta-se na metodologia por ele criada: pesquisa sobre o universo temático, tematização e problematização, mediante o que já dissemos. É pertinente esclarecer, nessa direção, que esse educador não a formulou nos marcos de uma Pedagogia Pós-Colonialista, embora o contexto sócio-histórico em que a Pedagogia do Oprimido foi escrita, bem como a teoria nela contida, permita-nos o embasamento. Ao afirmamos esses três momentos como partes de uma pedagogia que também pode ser considerada pós-colonialista, referimo-nos à interpretação que a eles lançamos, por entendermos que tais etapas corroboram princípios e práticas que se direcionam para ações problematizadoras das marcas da colonialidade ainda inscritas nas estruturas do currículo escolar contemporâneo.

A partir disso, corroboramos o escopo ético-humanista inerente à metodologia de reorganização curricular proposta por Paulo Freire no horizonte de uma Pedagogia da Libertação dos oprimidos em seu entendimento mais ampliado, no qual os subalternizados também se encontram considerados. Convém, agora, explicitar sucintamente os momentos aos quais aludimos:

1. O primeiro deles trata da investigação temática. Esta se configura em um estudo aprofundado sobre o contexto sociocultural e político-econômico em que se encontram envolvidos os sujeitos. É o estudo da realidade que mira conhecer a percepção que os indivíduos têm de suas próprias experiências existenciais, buscando a imersão nos mundos de vida das comunidades epistêmicas com o objetivo de apreender suas contradições, conflitos e interdições ao ser mais dos seres humanos. No raciocínio de 
Gouvêa da Silva (2004), o ápice da investigação temática é o de conhecer as negatividades concretas vivenciadas pelos sujeitos;

2. A tematização expressa a construção dos temas e dos contratemas geradores (estes se constituem na síntese temática, uma propositura voltada para desvelar as negatividades concretas do contexto local no qual se pretende a intervenção político-pedagógica) a partir da análise interdisciplinar das falas significativas enunciadas pelos sujeitos, objetivando a busca por seus significados no interior das comunidades epistêmicas investigadas tematicamente. Por intermédio da tematização se faz possível o planejamento coletivo e interdisciplinar dos conteúdos a serem ensinados e aprendidos, visando ao alargamento da consciência que têm os sujeitos sobre suas contexturas de vida;

3. O momento da problematização se traduz na radicalização dialógica de todo o processo de reorientação curricular popular crítico. É a instância do processo dialético consciência-mundo. Configura-se, nesses termos, como a dialetização entre o saber empírico dos sujeitos e o saber sistematizado advindo das diversas ciências, tendo como mirante a promoção de constantes rupturas de consciência e, por consequência, um estado de maior criticidade em relação aos contextos das experiências vividas. A problematização coopera, portanto, para o alargamento e a ressignificação das visões de mundo parciais dos indivíduos, o que requer um trabalho curricular propulsor do permanente processo de rupturas com os estados de consciência mágica e ingênua e da construção de uma consciência reflexivamente dialética e, por isso mesmo, problematizadora (Freire, 2005).

Diante do exposto, observamos a possibilidade da estruturação de uma práxis curricular balizada em um processo de articulação entre teoria e prática mediante a investigação de conflitos e contradições inerentes à atmosfera social que envolve a escola. Isso revela uma perspectiva crítica, contextualizada e problematizadora no que se refere à organização político-pedagógica das atividades escolares, evidenciando um fazer dialógico referenciado em princípios éticos, políticos e epistemológicos comprometidos com os ideais de transformação e humanização da realidade.

Dessa maneira, o diálogo aparece como ponto de partida para as situações gnosiológicas a serem desencadeadas no espaço-tempo da escola, por meio das quais o mundo humano pode ser apresentado como objeto de questionamento, de admiração e readmiração crítica sobre os problemas impeditivos à humanização dos sujeitos (Freire, 2005). Daí porque asseveramos que uma ação curricular imersa no diálogo problematizador com a realidade é capaz de contribuir para o processo de conscientização das pessoas em torno das condições sociais em que se encontram inseridas, uma vez que, ao apreenderem as razões da realidade, apreendem, também, seus desafios e suas responsabilidades diante do contexto social a ser transformado.

Nesses termos, o diálogo com a realidade concreta é fundamento imprescindível para um currículo escolar popular crítico, cujas demandas epistemológicas partem do conjunto das negatividades vivenciadas pela comunidade em um movimento constante de ação-reflexão-ação sobre o mundo (Freire, 2005). 
[A] epistemologia da negatividade [...] precisa ser apreendida como práxis para a implementação de um currículo crítico. Ter a negatividade como objeto de estudo dialógico para a organização do currículo [significa entendê-la como] um posicionamento político epistemológico, que, ao perscrutar metodologicamente as vítimas sobre os porquês das negatividades vivenciadas, busca realizar um cerco problematizador [...] à realidade desumanizadora, investigando, simultaneamente, contribuições e limites dos conhecimentos e saberes, tanto da comunidade quanto daquele que compõe os conteúdos selecionados a partir do acervo cultural sistematizado. (Gouvêa da Silva, 2004, p. 106)

Em outras palavras, significa transformar essa negatividade epistemológica em elemento potencializador de uma prática curricular amparada na valorização dos conflitos e das contradições da realidade social como elementos necessários ao processo educativo libertador, que estimula, por meio da problematização das situações limítrofes à existência humana, a ação crítico-transformadora dos sujeitos sobre a realidade opressora que os subjuga, o que caracteriza a educação como projeto político endereçado à humanização.

Decorre disso uma importante contribuição para os atos de ensinar e aprender, pois, ao problematizar os conteúdos pertinentes à análise da realidade investigada, o educador também os problematiza para si mesmo. Nessa perspectiva, a práxis de Paulo Freire acata o reconhecimento de que é impossível questionar algo a alguém e permanecer como espectador, sem comprometer-se com o processo de desvelamento crítico do contexto social tomado como objeto de rigorosidade epistemológica pela prática curricular.

Em acréscimo a esse raciocínio, Damke (1995) atesta que

aparece, aí, a função primordial da problematização: dar aos educandos [e também aos educadores] a possibilidade de irem se exercitando na prática de pensar criticamente e de tirar suas próprias interpretações dos fatos. $\mathrm{O}$ papel do professor adquire relevância [...]. Sua tarefa principal é problematizar. À medida que dialoga, cabe-lhe ir chamando a atenção para pontos obscuros ou ainda ingênuos, bem como para as relações entre as descobertas que estão sendo feitas pelos sujeitos envolvidos na situação gnosiológica. (Damke, 1995, p. 82)

De acordo com o que foi dito, a Figura 1 demonstra, esquematicamente, os momentos metodológicos da reorientação do currículo popular crítico fundamentados em uma concepção de educação libertadora.

Nesse sentido, a proposta de um currículo popular crítico ampara-se em uma concepção de sociedade como espaço de antagonismos, em que as diferentes situações sociais de interdição à humanização dos sujeitos são tomadas como objetos de estudo ético, político, pedagógico e epistemológico, visando, assim, ao desdobramento de um trabalho educativo capaz de questionar a ordem sociocultural vigente com suas marcas neocoloniais e, por consequência, forjar ações direcionadas à construção de outra organização societária, mais humana e permanentemente humanizante. 
Com efeito, transcorre dessa compreensão de educação uma visão crítica sobre o plano curricular, que passa a ser concebido como uma política do conhecimento estritamente vinculada ao processo de problematização da realidade com vistas à superação das relações de opressão e subalternidade a ela inerentes. Nesse prisma, o currículo admite uma perspectiva declaradamente emancipatória, na medida em que se fundamenta na possibilidade de os sujeitos transformarem o status quo vigente por intermédio de uma educação potencializadora da leitura e da ação crítica do e sobre o mundo.

1. Dialogicidade: investigação temática como ponto de partida do processo educativo, visando a dois objetivos básicos: a) descobrir a temática significativa dos educandos -> núcleo central das contradições que revelam o conjunto de contradições de um momento histórico; b) estudar o nível de percepção dos educandos com relação a esse núcleo de contradições.

2. Currículo interdisciplinar: trabalho coletivo, contínuo e sistemático dos sujeitos que refletem sua prática, compondo e recompondo o programa educacional, visando a favorecer o processo de conhecimento através dos seguintes passos: a) apreensão da situação existencial, codificada, como um todo -> visão global, ainda que fragmentada, da realidade; $b$ ) cisão do todo para a análise e compreensão das partes como pequenas totalidades; c) recomposição do todo cindido, a fim de descobrir a estrutura na qual os elementos se acham em relação dialética; d) análise crítica do que a situação existencial representa em relação a totalidades amplas.

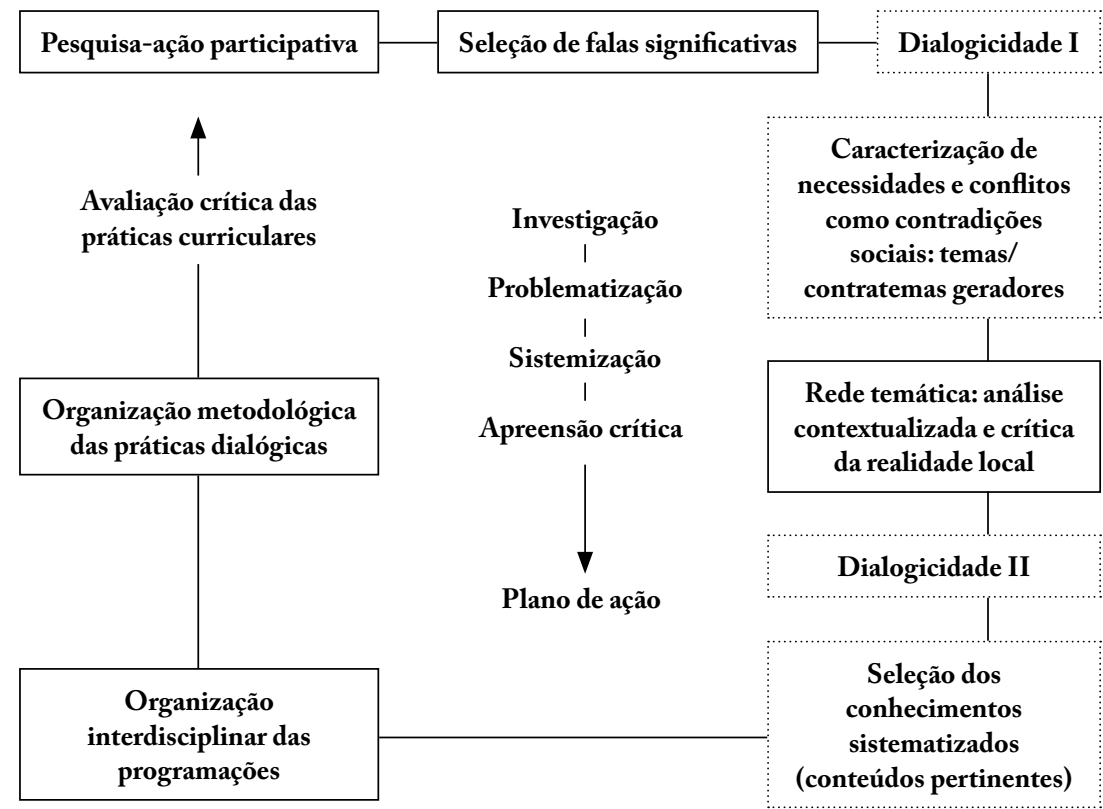

Figura 1 - Momentos metodológicos do currículo popular crítico.

Fonte: Gouvêa da Silva (2004, p. 275). 
Assim, por estar direcionada ao ideal de emancipação social, a esfera curricular estabelece uma estreita relação com a concretude da vida humana, oportunizando, nesse horizonte, um curriculo encarnado no contexto de vida dos sujeitos, bem como nos problemas sociais por eles vivenciados. Trata-se, dessa maneira, de um currículo que se insere criticamente na negatividade do real, visando à conscientização em torno das situações existenciais que provocam a desumanização das pessoas. Sobre isso, Gouvêa da Silva (2004) acentua que:

A inserção crítica no real proporciona o enfrentamento das tensões, a construção de novos planos de ação, de novas práticas sociais, alterando os relacionamentos socioculturais entre os envolvidos na superação possível e histórica das contradições que emanam dos conflitos. (Gouvêa da Silva, 2004, p. 135)

Em consonância a esse raciocínio, cabe ressaltar que essa concepção de currículo procura enxergar a escola pelo prisma da criticidade necessária para desnudar as contradições sociais, bem como persegue um posicionamento político empenhado nas possibilidades de resistência e superação delas. Abarca, ainda, a discussão sobre o papel do educador como intelectual engajado na tarefa de transformação da realidade, da instituição escolar como espaço público democrático no qual a voz da comunidade é ouvida com a finalidade da elaboração cultural, da emancipação e humanização dos sujeitos.

Dessa perspectiva advém o caráter pós-colonial da contribuição paulofreireana para os estudos curriculares, pois, ao colocar o oprimido no centro do processo de construção do conhecimento, torna-o visível, oportunizando-lhe o direito à fala e à voz. Por meio desse argumento, é importante pontuar que Paulo Freire, ao propor uma pedagogia política emancipatória e dialogal, não se propôs a falar pelos oprimidos, mas trabalhou eticamente pela construção de espaços nos e pelos quais as camadas oprimidas da sociedade pudessem se fazer protagonistas de seu processo formativo e de suas próprias histórias por meio do uso da palavra.

Isso implica em reconhecer que a teoria e a prática educacionais paulofreireanas são também a concretização de uma pedagogia das ausências, uma vez que trazem para o centro da história sujeitos humanos até então invisibilizados, transformando suas ausências simbolicamente construídas em presenças, tanto no interior dos processos de ensino e de aprendizagem quanto no âmbito da tessitura social mais ampla, fato que promove a abertura de espaços para a visualização e a audição de seus conhecimentos e experiências existenciais como elementos de conscientização e de transformação social.

No sentido dessa discussão, convém destacar que Paulo Freire, ao problematizar os pressupostos da educação bancária, não denunciou apenas uma ação educacional vertical, instrumentalizada e descontextualizada, mas, sobretudo, uma estrutura social de opressão refletida através do trabalho pedagógico. Ele percebeu, com perspicácia, que é essa estrutura social opressora o solo no qual se erguem práticas educacionais bancárias, que viabilizam representações abstratas da realidade e desencadeiam políticas e práticas curriculares legitimadoras de um bem comum 
universal $^{3}$, além de promoverem violência epistêmica (Santos, 2008; Spivak, 2010) ao escamotear a realidade local, seus conflitos e suas contradições sociais como fundamentos para a organização dos saberes e atividades curriculares.

Evidenciamos, ainda, que esse bem comum universal, sustentado por positividades estrangeiras, anula a visualização do sofrimento como realidade objetiva que recai sobre os sujeitos (Zuin et al., 1999), além de se constituir como empecilho à "[...] desnaturalização das formas canônicas de aprender-construir-ser no mundo" (Lander, 2005, p. 39) enunciadas pela racionalidade eurocêntrica universalizante. Gouvêa da Silva (2004), sustentado pelo pensamento de Paulo Freire, capta com sensibilidade essa anulação ao afirmar que,

[...] independentemente dos sujeitos e das especificidades dos contextos, observa-se na rotina discursiva da escola uma exacerbação de positividades, instituindo práticas nem sempre tão coerentes com os princípios humanistas proclamados. Muitas vezes, o sofrimento e as necessidades materiais, a humilhação sociocultural e o desprezo epistemológico são relativizados, secundarizados, ou mesmo considerados exigências corretivas para o êxito dos objetivos humanistas das positividades pedagógicas. É o incontestável primado do bem, que fundamenta a positividade rousseauniana da prática educacional negativa. (Gouvêa da Silva, 2004, p. 90, grifo do original)

Essa visão ideológica das relações escola-realidade é a que fundamenta, em menor ou em maior grau, grande parte dessas positividades educacionais contemporâneas, colonizando cognitivamente o plano da prática curricular ao definir

[...] os critérios apriorísticos adotados para a seleção dos conhecimentos sistematizados que comporão o rol de conteúdos das disciplinas, as metodologias explanativas priorizadas no processo de ensino-aprendizagem, a organização de uma gramática escolar prescritiva, a submissão institucional do tempo-espaço pedagógico ao administrativo, [...]. (Gouvêa da Silva, 2004, p. 99)

Nesses termos, observamos o pretenso desejo da afirmação de uma universalidade apriorística e assentada em uma pseudoneutralidade epistemológica, já denunciada por Vandana Shiva (2003) quando refletiu sobre a devastação de sistemas inteiros de tradições transeculares do conhecimento pelo colonialismo/imperialismo da racionalidade científica ocidental, o que provocou, na ótica de Germano (2008), múltiplas estratégias de produção da inferioridade simbólica do outro, as quais incidi-

3 Esse bem comum universal ao qual nos referimos não é aquele amparado nos princípios dos Direitos Humanos. No âmbito deste texto, podemos entendê-lo como aqueles discursos que apregoam "positividades" descontextualizadas e consideradas necessárias à melhoria das condições de vida e dos contextos escolares dos sujeitos. Geralmente, amparam-se em noções cristalizadas de democracia e de cidadania, mas que escondem, paradoxalmente, interesses de classe e frações de classe que corroboram o não questionamento do status quo das sociedades. 
ram diretamente na formação de sujeitos humanos alheios ao seu próprio universo sociocultural, político-econômico e cognitivo-epistêmico.

Essa perspectiva bancária entranhada no devir pedagógico promove a naturalização das relações que se desdobram no âmbito educativo, refletindo um certo tipo de universalismo imperialista que se reveste sob a forma de pacotes educacionais exógenos destinados a diferentes paisagens socioeducacionais em suas múltiplas configurações. Tais pacotes são assimilados e defendidos como elementos civilizacionais capazes de corrigir desvios em relação ao padrão supostamente normal e civilizado, que é a experiência dos grandes centros do mundo. A esse respeito, Lander (2005) nos mostra como diferentes recursos históricos têm servido para sustentar a concepção eurocêntrica de evolucionismo social. Expressa ele:

Os diferentes recursos históricos (evangelização, civilização, o fardo do homem branco, modernização, desenvolvimento, globalização) têm todos como sustento a concepção de que há um padrão civilizatório que é supostamente superior e normal. Afirmando o caráter universal dos conhecimentos científicos eurocêntricos abordou-se o estudo de todas as demais culturas e povos a partir da experiência moderna ocidental, contribuindo desta maneira para ocultar, negar, subordinar ou extirpar toda experiência ou expressão cultural que não corresponda a esse dever ser [...]. (Lander, 2005, p. 36)

Ao problematizar os fundamentos da educação bancária, Paulo Freire (2005) observa que há uma valorização ingênua em torno de um suposto bem comum universal transcendente à prática política e sociocultural de indivíduos e grupos sociais, o que contribui para colocar em movimento uma ação educativa que não possui relação orgânica com as realidades nas quais se realiza. Praticadas dentro desse modelo pré-formatado, distanciam-se das necessidades concretas dos sujeitos no que concerne à discussão em torno das situações-limite ${ }^{4}$ que os afetam.

$\mathrm{O}$ caráter sagrado dessas positividades abstratas, fundamentadas em um suposto humanismo civilizatório, instituiu-se, mediante analisa Gouvêa da Silva (2004), em mentalidades e espíritos curriculares, transformando-se em rotinas pedagógicas que as têm como valores educacionais incontestáveis em favor do primado do bem.

A hegemonia do discurso do bem comum universal, inerente aos modismos pedagógicos contemporâneos, constitui-se, portanto, em uma variante mais sutil, embora não menos eurocêntrica, dessa perspectiva ideológica da construção da inferioridade simbólica do outro, que, ao revestir-se de intencionalidades positivas, bumanistas e universais, colabora para o desencadeamento de práticas de opressão no âmbito das ações curriculares, estabelecendo relações de subalternidade e afirmando uma verdade positiva desumanizadora (Freire, 2005; Gouvêa da Silva, 2004).

No horizonte desse pensamento, argumentamos, com base em Freire (2005), que a subalternidade no campo curricular é consequência dessa inferiorização sim-

4 Sobre o entendimento das situações-limite, conferir: Osowski (2010). 
bólica, sendo construída a partir da interdição da possibilidade de enunciação das vítimas do sistema, uma vez que são as positividades apriorísticas e estrangeiras resvaladas por meio de um discurso homogeneizador do bem comum universal - que orientam a organização dos saberes e das práticas escolares, dificultando, nesse sentido, uma ação curricular entranhada no balbucio ${ }^{5}$ (Achugar, 2006) das histórias e das contradições societárias locais. Os marginais são silenciados e, quando isso ocorre, as bases da subalternidade são construídas como lugares de carência em razão da negação de suas falas.

Nesses termos, o discurso pedagógico dominante produz lugares de enunciação curricular considerados periféricos, os quais, para a razão indolente (Santos, 2009), para o olhar epistemológico dominante, traduzem-se em lugares carentes de fala. Ou seja, a supremacia/autoridade dessa enunciação discursiva preconiza aqueles que não têm nada a dizer, bem como credibiliza aquilo que é passível de ser dito. Decorre disso o fato de que "[...] sempre se pode dizer que há um Outro que nos fala e que, por sua vez, o Outro fala em outros Outros. O centro, os múltiplos centros fazem falar a margem" (Achugar, 2006, p. 20), a partir de uma postura universalista e colonizadora.

Corroboramos, mediante isso, o raciocínio de que o primado do bem, propalado pelas propostas curriculares contemporâneas, reflete a

[...] posição daqueles que, da metrópole, ou do jardim da academia, realizam a operação de decretar que na periferia (posição ubíqua, relacional e situacional) não há linguagem, não há boca, não há discurso. Quer dizer, a periferia, a margem, é lugar da carência. Alguns afirmam - em uma lógica em que periferia e margem são, se não sinônimos, parentes próximos do subalterno ou do excluído - que o lugar da carência radical é o do subalterno, o do excluído. O subalterno - de acordo com Gayatri Spivak - não pode falar, pois se fala já não o é. O subalterno é falado pelos outros. (Achugar, 2006, p. 20, grifo nosso)

$\mathrm{Na}$ esteira do que nos diz Achugar (2006), compreendemos que grande parte da prática educacional contemporânea está mergulhada na unidirecionalidade das propositivas morais, na imposição de valores preestabelecidos, na desconsideração de contextos socioculturais, bem como na ausência da participação consciente e ativa dos sujeitos concretos no âmbito organizativo da escola.

Isso nos revela as marcas inocultáveis de uma pedagogia colonizadora e construtora de subalternidade, por intermédio da qual a voz dos oprimidos é silenciada por uma ética educacional eurocêntrica, que os concebe como seres carentes de fala e identidade, necessitando, por isso mesmo, da promessa ideológica do vir-a-ser positivo.

5 O balbucio sugerido por Achugar (2006) se revela como forma de reivindicação da alteridade dos subalternos, como uma estratégia de combate à violência epistêmica que silencia a voz daqueles que não têm espaço no arranjo societário contemporâneo por serem considerados sujeitos de não valor, errôneos, fora do lugar e fadados a uma perspectiva de mundo projetada a partir dos grandes centros. 
Assim sendo, esse tipo de prática educacional, mediada pela hegemonia dos parâmetros universais e exógenos, subalterniza os sujeitos, excluindo-lhes e negando-lhes o direito legítimo à alteridade discursiva, sem a qual continuarão na condição de serem falados e representados pelo discurso dos outros, como observa Spivak (2010).

No imo dessa discussão, concordamos com Gouvêa da Silva (2004) quando destaca que

[...] precisamos construir a nossa própria positividade, pois a materialidade da libertação se concretiza somente a partir das vozes das vítimas desse sistema-mundo dominador. Superar essa negatividade exógena seria o primeiro desafio de um projeto educacional crítico. [...] Nessa perspectiva, as manifestações negativas teriam sua gênese não mais na imposição de um contexto colonizador, mas constituiriam um mal necessário, decorrência de um movimento cultural endógeno comprometido com a reprodução das condições mais adequadas à sobrevivência, à preservação e preparação do sujeito para a vida, para o trato das condições desfavoráveis impostas pela realidade. (Gouvêa da Silva, 2004, p. 99-100)

A construção da nossa própria positividade, consoante à reivindicação explícita na fala de Gouvêa da Silva (2004) e como já defendia Paulo Freire na extensão de sua práxis, não pode prescindir do direito ao exercício da voz como ato político. Uma prática curricular amparada naquilo que a realidade apresenta como situações- limite busca considerar o discurso dos sujeitos como condição precípua para uma proposta educacional engajada com a promoção da justiça social e cognitiva, tendo em vista que "[...] a fala do excluído representa o ataque mais radical à pretensão de totalidade que o sistema instituído pode sofrer" (Gouvêa da Silva, 2004, p. 103).

Com esse pensamento, podemos apreciar que uma ação curricular entranhada na fala dos excluídos, na carnalidade de suas enunciações sobre o mundo, é partejar uma alternativa possível à desconstrução da subalternidade, haja vista que, segundo Spivak (2010), a condição fulcral da subalternidade é a situação de silêncio, a interdição à voz. Nesse sentido, observamos a posição de cumplicidade das atividades curriculares mediadas por uma positividade exógena que julga poder falar em nome de. Agir dessa forma é contribuir para a reprodução das estruturas de poder, de opressão e de exploração, mantendo os subalternos, os oprimidos e os explorados em condições de invisibilidade e de silêncio (Spivak, 2010).

Partindo dessa perspectiva, a elaboração da nossa própria positividade, uma positividade endógena, como nos advertiu Freire (2005) e como reforça Gouvêa da Silva (2004), propicia ouvir o balbucio, nas palavras de Hugo Achugar (2006), daqueles que não têm voz nem lugar no arranjo societário contemporâneo, pois as leis ditadas pelo projeto imperialista silenciam as vozes dos marginais, não lhes dando permissão para narrar (Spivak, 2010).

Defendemos, portanto, uma pedagogia do subalterno capaz de orientar a produção de um currículo encarnado na materialidade da vida humana como espaço de visibilidade e de audibilidade dos sujeitos e de suas enunciações, um espaço pos- 
sível para a desconstrução da subalternidade e para a problematização e superação das condições objetivas e subjetivas de opressão. Em outras palavras, alinhamos a nossa defesa a uma propositiva contrária à hegemonia das positividades ingênuas e a-históricas propaladas por uma pedagogia eurocêntrica, opressora e produtora de violência e injustiça cognitivas (Lima, 2014).

É diante dessa abordagem que argumentamos sobre um balbucio curricular emitido pelos subalternizados e oprimidos como possibilidade para a construção do próprio discurso, do próprio testemunho sobre o mundo, o que, em outras palavras, significa defender a enunciação de uma narrativa educacional capaz de recuperar histórias locais e suas contradições como produtoras de conhecimento e como caminho para a desconstrução das condições de invisibilidade e de silêncio.

Enfatizamos, nessa direção, o diálogo como uma racionalidade problematizadora contrária à tutela da voz e favorável à coparticipação dos sujeitos no ato de pensar o mundo em sua miríade de contradições, tensões e conflitos sociais. Nessa ótica, o momento dialógico se transforma em um lugar de enunciação no qual os oprimidos e subalternizados podem falar e ser ouvidos em suas alteridades discursivas. Corroboramos, desse modo, a afirmativa de que uma educação consubstanciada no diálogo oportuniza a criação de

[...] espaços por meio dos quais o sujeito subalterno possa falar para que, quando ele ou ela o faça, possa ser ouvido(a). [...], não se pode falar pelo subalterno, mas pode-se trabalhar contra a subalternidade, criando espaços nos quais o subalterno possa se articular e, como consequência, possa também ser ouvido. (Almeida, 2010, p. 14, grifo do original)

A partir dessas palavras, observamos que o diálogo, entendido como um lugar de enunciação no âmbito de uma educação como prática da liberdade, apresenta um aspecto eminentemente político e cultural, pois traz, conforme acreditamos, a possibilidade da organização de um currículo dos conhecimentos ausentes e silenciados, ou seja, uma ação educativa que possibilita ver e ouvir aquilo que foi ocultado para oprimir, tornando visível e audível, por intermédio da problematização das negatividades da existência humana, práticas e discursos que legitimam a dominação e a exploração dos sujeitos.

Cumpre destacar, ainda, que esse lugar de enunciação se nutre da "[...] inconformidade de as coisas serem como são" (Cortella, 2006, p. 157), fazendo-se lugar ético-político da construção de uma práxis pedagógica encarnada na materialidade da vida e cujas ações educacionais por ela articuladas objetivem a produção de "[...] imagens radicais e desestabilizadoras dos conflitos sociais, [...], imagens capazes de potenciar a indignação e a rebeldia" (Santos, 1996, p. 17), impulsionando, por consequência, a formação de subjetividades rebeldes e inconformistas diante do sofrimento humano (Santos, 2008).

Uma práxis pedagógica assim definida celebra a construção de um conhecimento prudente para uma vida decente (Santos, 2006), visto que se engaja em um trabalho curricular de tradução da realidade — investigação temática/tematização/ problematização, no vocabulário paulofreireano - com o intuito de nela enxergar 
aquilo que oprime e subalterniza para, então, suscitar um conhecimento como projeto de conscientização para a libertação em relação ao que é injusto e desumano.

Esse trabalho curricular de tradução da realidade só é possível na medida em que se abrem espaços para o aprendizado a partir do outro e com o outro, empenhando-se na subversão das estruturas de subalternidade que ainda mantêm populações inteiras em condições de invisibilidade e de silêncio. Dessa forma, o êxito dessa tradução implica na ampliação do número de falantes mobilizados na produção de um conhecimento que anseie pela emancipação social e contribua para o enriquecimento das capacidades humanas quanto à manutenção da vida $\mathrm{e}$ da dignidade das pessoas.

Consideramos, por fim, a pedagogia do oprimido e do subalterno como propulsora de um curriculo encarnado na objetividade da vida humana e como um chamamento político à luta e à esperança de que um novo tempo é possível, o que nos leva a crer, em conjunto com Paulo Freire (2001, p. 40), que "nossa luta de hoje não significa que necessariamente conquistaremos mudanças, mas sem que haja essa luta, hoje, talvez as gerações futuras tenham de lutar muito mais. A história não termina em nós: ela segue adiante".

\section{ALGUMAS CONSIDERAÇÕES COMO PONTOS DE PARTIDA PARA A AMPLIAÇÃO DO DEBATE}

No decorrer do artigo em apreço, procuramos evidenciar alguns dos argumentos pelos quais é possível perceber os horizontes pós-coloniais do pensamento político-pedagógico de Paulo Freire, especialmente em sua obra Pedagogia do Oprimido, livro no qual está presente uma forma de racionalidade socioeducacional que traz manifestas a reflexão e a problematização em torno dos matizes da colonialidade que se desdobram no corpo social e, por extensão, na esfera educacional, a exemplo da crítica às metanarrativas educacionais revestidas de positividades universalizantes no âmbito dos processos curriculares contemporâneos.

A essa afirmação, acrescentamos o fato de que o conjunto da obra de Paulo Freire traz importantes elementos para as análises pós-coloniais, tendo em vista que se caracteriza, concomitantemente, como crítica radical aos aspectos coloniais e neocoloniais inerentes ao que ele denominou educação bancária, como também se traduz em práxis libertadora orientada para a promoção de um pensamento crítico-atuante capaz de ler consciente e concretamente o mundo. Nesses termos, percebemos uma pedagogia de dimensões claramente políticas, endereçada ao processo de descolonização cognitiva por meio da possibilidade de uma educação dialógica para emergência da consciência crítica, constituindo-se, portanto, como um elemento fundamental para o desdobramento de ações pós-coloniais no campo educacional formal e não formal (Lima, 2011).

Pudemos observar, amparados na análise pós-colonial sobre a Pedagogia do Oprimido, que o primado do discurso do bem comum universal, inerente a muitas propostas curriculares contemporâneas, propicia a manutenção de uma hegemonia eurocêntrica no plano educacional, cujos parâmetros universais e exógenos 
promovem a subalternidade curricular, por intermédio da qual se nega a alteridade discursiva dos oprimidos diante da construção de um currículo escolar a eles coerente, afirmando, nesses termos, a condição de serem falados/representados pelo discurso de outros.

Outrossim, de acordo com as contribuições de Achugar (2006), sinalizamos que essa condição de subalternidade reforça a produção/reprodução de um planeta curricular sem enunciação própria, ou seja, um planeta curricular sem boca, posto que seus objetivos formativos, como também as práticas por ele desencadeadas, partem de um centro enunciativo hegemônico, impondo proposições normativas que definem conteúdos educacionais divorciados dos contextos socioculturais nos quais se aplicam.

Por fim (ou para aprofundar o debate?), sugerimos a pedagogia de Paulo Freire como um lugar de enunciação no qual se abrem possibilidades para o desencadeamento de ações educacionais dialógicas e praxiológicas capazes de visibilizar e escutar sujeitos e seus falares, oportunizando, assim, as ressonâncias de um balbucio curricular emitido pelos oprimidos e subalternizados na busca pela construção de seus discursos sobre o mundo. Isso corrobora o anúncio de uma narrativa educacional como projeto político e pós-colonialista adequado à recuperação de histórias locais, suas contradições e negatividades como produtoras de um conhecimento insubmisso e combatente aos muitos avatares da opressão, da exploração e da subalternidade que inviabilizam a vida digna e a humanização de muitas pessoas.

\section{REFERÊNCIAS}

Achugar, H. Planetas sem boca: escritos efêmeros sobre arte, cultura e literatura. Tradução de Lyeslei Nascimento. Belo Horizonte: Editora UFMG, 2006.

Almeida, S. R. G. Prefácio: apresentando Spivak. In: Spivak, G. C. Pode o subalterno falar? Tradução de Sandra Regina Goulart Almeida, Marcos Pereira Feitosa e André Pereira Feitosa. Belo Horizonte: Editora UFMG, 2010.

Apple, M. W.; Buras, K. L. Currículo, Poder e Lutas Educacionais: com a palavra, os subalternos. Tradução de Ronaldo Cataldo Costa. Porto Alegre: Artmed, 2008.

Arendt, H. Homens em tempos sombrios. Tradução de Denise Bottmann. São Paulo: Companhia das Letras, 1987.

Bourdieu, P. Sociologia. Introdução e organização de Renato Ortiz. São Paulo: Ática, 1983.

. Os usos sociais da ciência: por uma sociologia clínica do campo científico. Tradução de Denice Barbara Catani. São Paulo: Editora UNESP, 2004.

Bourdieu, P. Esboço de auto-análise. Tradução de Sergio Miceli. São Paulo: Companhia das Letras, 2005a.

. A economia das trocas simbólicas. 6. ed. Tradução de Sergio Miceli. São Paulo: Perspectiva, 2005b. 
Cortella, M. S. A escola e o conhecimento: fundamentos epistemológicos e políticos. 10. ed. São Paulo: Cortez, Instituto Paulo Freire, 2006. (Coleção Prospectiva. v. 5).

Dамке, I. R. O processo do conhecimento na pedagogia da libertação: as idéias de Freire, Fiori e Dussel. Petrópolis: Vozes, 1995.

Freire, P. Pedagogia do Oprimido. 42. ed. Rio de Janeiro: Paz e Terra, 2005.

. Pedagogia dos sonhos possíveis. Organização e apresentação de Ana Maria Araújo Freire. São Paulo: Editora UNESP, 2001.

Fiori, E. M. F. Prefácio. In: Freire, P. Pedagogia do Oprimido. 42. ed. Rio de Janeiro: Paz e Terra, 2005.

Germano, J. W. A produção simbólica da inferioridade. In: Coelho, W. N. B. A cor ausente. Belo Horizonte: Mazza, 2008.

Goodson, I. F. Currículo: teoria e história. 12. ed. Tradução de Attílio Brunetta. Petrópolis: Vozes, 2012.

Gouvêa Da Silva, A. F. A construção do curriculo na perspectiva popular crítica: das falas significativas às práticas contextualizadas. 2004. 375f. Tese (Doutorado em Educação: currículo) - Pontifícia Universidade Católica de São Paulo, São Paulo, 2004.

LAnder, E. (Org.). A colonialidade do saber: eurocentrismo e ciências sociais. Buenos Aires: Consejo Latinoamericano de Ciencias Sociales, 2005.

Lima, J. G. S. A. Paulo Freire e a Pedagogia do Oprimido: afinidades pós-coloniais. 2011. 136f. Dissertação (Mestrado em Desenvolvimento Regional; Cultura e Representações) — Universidade Federal do Rio Grande do Norte, Natal, 2011.

. Currículo Encarnado: cartografia simbólica e afinidades pós-coloniais. 2014. 134f. Tese (Doutorado em Educação) - Universidade Federal do Rio Grande do Norte, Natal, 2014.

Lopes, A. C.; Macedo, E. (Org.). Currículo: debates contemporâneos. 2. ed. São Paulo: Cortez, 2005. (Série Cultura, Memória e Currículo. v. 2). .; __ Teorias de currículo. São Paulo: Cortez, 2011.

Moreira, A. F.; Silva, T.T. (Org.). Curriculo, cultura e Sociedade. Traduzido por Maria Aparecida Baptista. 10. ed. São Paulo: Cortez, 2008.

Mota Neto, J. C. Por uma Pedagogia decolonial na América Latina: reflexões em torno do pensamento de Paulo Freire e Orlando Fals Borda. Curitiba: CRV, 2016.

Nogueira, M. A.; Nogueira, C. M. M. Bourdieu E̋ a Educação. 3. ed. Belo Horizonte: Autêntica, 2009.

Osowski, C. I. Situações-limites. In: Streck, D. R.; Redin, E.; Zitros ki, J. J. (Org.). Dicionário Paulo Freire. 2. ed. Belo Horizonte: Autêntica, 2010.

Quayson, A. Postcolonialism: theory, practice or process? Oxford: Polity Press, 2000.

Quijano, A. Colonialidade do poder e classificação social.In: Santos, B. S.; Meneses, M. P. (Org.). Epistemologias do Sul. São Paulo: Cortez, 2010. p. 73-117.

Santos, B. S. Para uma pedagogia do conflito. In: Silva, L. H.; Azevedo, J. C.; Santos, E. S. Novos mapas culturais, novas perspectivas educacionais. Porto Alegre: Sulina, 1996. 
Santos, B. S. A gramática do tempo: para uma nova cultura política. 2. ed. São Paulo: Cortez, 2008. (Coleção para um Novo Senso Comum. v. 4).

. Crítica à razão indolente: contra o desperdício da experiência. 7. ed. São Paulo: Cortez, 2009.

Shiva, V. Monoculturas da Mente: perspectiva da biodiversidade e da biotecnologia. Tradução de Dinah de Abreu Azevedo. São Paulo: Gaia, 2003.

Silva, T.T. Documentos de identidade: uma introdução às teorias do currículo. 3. ed. Belo Horizonte: Autêntica, 2011.

Spivak, G. C. Pode o subalterno falar? Tradução do original em inglês de Sandra Regina Goulart Almeida, Marcos Pereira Feitosa e André Pereira Feitosa. Belo Horizonte: Editora UFMG, 2010.

Shor, I. Um livro perturbador a respeito da educação. In: Gadotti, M. Paulo Freire: uma biobibliografia. São Paulo: Cortez: Instituto Paulo Freire; Brasília,DF: UNESCO, 1996.

Streck, D. R. Da pedagogia do oprimido às pedagogias da exclusão: um breve balanço crítico. Revista Educação E Sociedade, v. 30, n. 107, p. 539-560, mai.-ago. 2009.

Zuin, A. A. S.; Pucci, B.; Ramos-de-Oliveira, N. Adorno: o poder educativo do pensamento crítico. Rio de Janeiro: Vozes, 1999.

\section{SOBRE OS AUTORES}

José Gllauco Smith Avelino de Lima é doutor em educação pela Universidade Federal do Rio Grande do Norte (UFRN). Professor do Instituto Federal de Educação, Ciência e Tecnologia do Rio Grande do Norte (IFRN). E-mail: jose.avelino@ifrn.edu.br

Marta Maria Castanho Almeida Pernambuco foi doutora em educação pela Universidade de São Paulo (USP). Professora da Universidade Federal do Rio Grande do Norte (UFRN).

E-mail:mmcaper@gmail.com

(in memoriam)

Recebido em 20 de setembro de 2017

Aprovado em 12 de março de 2018 